\title{
$O$ acontecer da compreensão e o esforço da recepção: experiência estética em Hans-Georg Gadamer e Hans Robert Jauss
}

Rafael Barros de Oliveira

Doutorando na Universidade Paris-Nanterre

\section{Introdução}

A relação entre verdade e método tem lugar central na filosofia hermenêutica de Hans-Georg Gadamer. Sua tese forte de que haveria dimensões da verdade inacessíveis pelo emprego exclusivo de procedimento metódicos foi historicamente confrontada com a objeção segundo a qual Gadamer oporia radicalmente os dois termos - a saber, "verdade" e "método" - e, portanto, descartaria por completo o papel desses expedientes na busca pela verdade e pelo sentido. Neste artigo, buscarei mostrar a incorreção dessa leitura, apontando para a distinção e para a interação de duas dimensões possíveis da experiência hermenêutica, ilustradas em nossa relação com obras de arte. Com isso, pretendo apontar para a dialética entre "explicação" e "compreensão" que perpassa a tradição hermenêutica, ressaltando os encaminhamentos que lhe foram dados por Gadamer.

O caso particular da consciência estética, da relação interpretativa com fenômenos artísticos, não é nem arbitrário nem anódino, uma vez que Gadamer 
lhe atribui protagonismo, no percurso argumentativo de Verdade e método, como a instância na qual a insuficiência de procedimentos metódicos para apreender a verdade em seu todo se manifesta a nós de maneira mais clara:

Será que não deve haver nenhum conhecimento na arte? Não há na experiência da arte uma reivindicação à verdade, que sendo certamente diversa da ciência, certamente também não lhe será inferior? E será que não reside a tarefa da estética justamente em fundamentar que a experiência da arte é uma forma de conhecimento dos sentidos, que transmite à ciência os últimos dados, a partir dos quais póe-se a construir o conhecimento da natureza, certamente também diferente de todo conhecimento ético da razão e, aliás, de todo o conhecimento conceitual, mas que é, contudo, conhecimento, ou seja, transmissão da verdade:沁

O caminho que culminará na consciência hermenêutica tem na análise fenomenológica da consciência estética seu ponto de partida. Isso porque a arte, talvez mais do que qualquer outra forma de produção de sentido, resiste incessantemente às tentativas de controle científico-metódicas 2 Ao examinar os motivos desse suposto fracasso epistemológico, Gadamer pretende identificar traços fundamentais da relação interpretativa, que se reproduzirão em fenômenos de sentido de outros tipos - em especial a história - e, com isso, mapear os contornos da experiência hermenêutica em geral:

${ }^{\mathrm{I}}$ Gadamer, Hans-Georg. Verdade e método. 3 ${ }^{\underline{a}}$ ed. Petrópolis: Vozes, 1999, p. 169 [103]. Doravante "VM".

2 "O ponto de partida de minha teoria hermenêutica foi justamente que a obra de arte é uma provocação para nossa compreensão porque se subtrai sempre de novo às nossas interpretações e se opóe com uma resistência insuperável a ser transportada para a identidade do conceito. (...) É justamente por isso que o exemplo da arte exerce a função orientadora, que a primeira parte de Verdade e método I possui para o conjunto de meu projeto de uma hermenêutica filosófica. Isso torna-se de todo modo claro, se considerarmos 'a verdade da arte' na multiplicidade e multivariedade infinita de seus 'enunciados'." "Entre fenomenologia e dialética - tentativa de uma autocrítica” [1985]. In: Gadamer, Hans-Georg. Verdade e método II. Petrópolis: Vozes, 2002, p. is [8]. Doravante "VMII". 
Se quisermos saber o que é a verdade nas ciências do espírito, teremos então de dirigir a questão da filosofia ao conjunto dos procedimentos das ciências do espírito (...). Não iremos ter de aceitar a resposta da auto-evidência das ciências do espírito, mas teremos de indagar o que é, na verdade, sua compreensão. Na preparação dessa pergunta de longo alcance o que poderá servir, em especial, será a indagação sobre a verdade da arte, justamente por que inclui a compreensão da experiência da obra de arte, ou seja, representa até mesmo um fenômeno hermenêutico, e não, certamente, no sentido de um método científico. A compreensão pertence, antes, ao próprio encontro com a obra de arte, de maneira que apenas do ponto de vista do modo de ser da obra de arte é que se pode aclarar essa pertença.

Se o fio condutor de Verdade e método nos encaminha para reconhecer a ligação ou o pertencimento ontológico fundamental à linguagem e suas implicações epistemológicas que transcendem o domínio estreito da ciência moderna, a argumentação de Gadamer não descarta totalmente - ao contrário do que lhe opuseram alguns de seus críticos - o emprego desses procedimentos científicos. Nesse sentido, o gesto hermenêutico de expor os limites da subjetivação da experiência estética, de um lado, e das reduções conceituais idealistas, de outro, tem antes a pretensão de situar nossa relação com a arte num contexto simbólico e significante mais amplo, no interior do qual procedimentos metódicos de análise ainda têm seu lugar.

Para sustentar essa leitura da abordagem hermenêutica da experiência estética na obra de Gadamer, procederei em três passos: I. uma breve exposição das consideraçóes sobre a consciência estética em Verdade e método; 2. a tentativa de elevação do conceito de horizonte a fundamentação epistemológica da estética por Hans Robert Jauss; 3. uma ênfase no caráter ontológico da linguisticalidade, a partir do qual as questóes de método devem ser reposicionadas. Apontarei para o papel fundamental da distinção entre o esforço de interpretar e o acontecer da compreensão na construção da abordagem hermenêutica da experiência estética.

${ }^{3}$ VM, p. 173 [106]. 


\section{Experiência e verdade na consciência estética}

A retomada da pergunta pela verdade na arte emerge em Gadamer em contraposição a duas etapas do desenvolvimento histórico da filosofia: de um lado, a filosofia kantiana, em sua formulação transcendental do escopo e das limitações do conhecimento - na Crítica da razão pura - e a consequente subjetivação das categorias estéticas no juízo reflexivo - na Crítica da faculdade de julgar; de outro lado, aquilo que Gadamer identifica como uma tentativa - ou melhor, uma tentação - de subsumir fenômenos artísticos a conceitos, que ele atribui à estética do idealismo alemão e cujo paradigma máximo se encontraria em Hegel, uma leitura da obra de arte como representação de uma ideia que a um só tempo a antecede e transcende. Face a essas duas concepçôes estéticas, caberia perguntar se haveria algum tipo de verdade na e da arte que pudesse escapar simultaneamente à redução subjetivista e à redução conceitual?

Sem pretender dar conta do itinerário argumentativo mobilizado por $\mathrm{Ga}$ damer para enfrentar essa questão - o que extrapolaria, e muito, o escopo e os limites deste trabalho -, cabe, contudo, retomar seus contornos gerais, os quais permitirão fundamentar a emergência - ou mais propriamente a retomada - do conteúdo de verdade intrínseco e próprio aos fenômenos artísticos. Com efeito, é isso o que está em jogo na primeira parte de Verdade e método, como fica patente em seu título: "A liberação da questão da verdade desde a experiência da arte" ${ }^{4}$

A dupla oposição à subjetivação da estética, de um lado, e à sua conceitualização radical, de outro, se faz em Gadamer por meio da conjunção de duas linhas argumentativas: a retomada das dimensões cognitiva, intersubjetiva e moral das categorias estéticas a partir da tradição humanista e a abordagem fenomenológica da obra de arte como presentação e não representação.

${ }^{4}$ Cf. Gutiérrez-Pozo, Antonio. "El arte como realidad trasformada en su verdad. La rehabilitación hermenéutica de la estética en Hans-Georg Gadamer”. In: Kriterion, v. 59, n. 139 (2018), pp. 35-54. 


\section{I.I Crítica da subjetivação transcendental}

Quanto ao primeiro movimento, inserido no gesto gadameriano de denúncia do "preconceito contra preconceitos" que caracterizou o Esclarecimento.5estava em jogo uma crítica à estética do gênio, à ideia de uma subjetividade criativa e criadora de sentido. Gadamer procura mostrar a maneira como a filosofia kantiana e pós-kantiana opera uma ressignificação de conceitos herdados da tradição

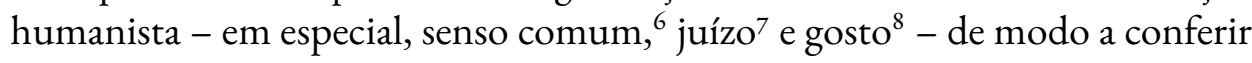

s “(...) há realmente um preconceito da Aufklärung que suporta e determina sua essência: esse preconceito básico da Aufklärung é o preconceito contra os preconceitos, enquanto tais, e, com isso, a despotenciação da tradição". VM, p. 407 [275].

6 "Enquanto que na Inglaterra e nos países românicos o conceito de sensus communis designa ainda hoje não apenas uma palavra-de-ordem crítica, mas uma qualidade geral do cidadão, na Alemanha os adeptos de Shaftesbury e de Hutcheson, no século XVIII, não assumiram o conteúdo político-social, que se acreditava haver no sensus communis. (...) Assimilou-se, é verdade, o conceito sensus communis, mas, na medida em que era inteiramente despolitizado, o conceito perdeu seu específico significado crítico. Passou-se a entender, sob sensus communis, apenas uma faculdade teórica, ou seja, a força do juízo teorético, que se colocou ao lado da consciência (Bewusstsein) ética (a consciência, Gewissen) e o gosto.” VM, p. 7I [32].

7 "De fato, a atividade do juízo, de subsumir o particular no universal, de reconhecer algo como o caso de uma regra, não pode ser demonstrada logicamente. O juízo encontra-se fundamentalmente deslocado, por causa de um princípio que poderia guiar sua aplicação. Para seguir esse princípio, seria necessário lançar mão de outro juízo, como observa Kant (...). Não pode pois ser pregado genericamente, mas apenas exercitado de caso a caso e é, como tal, mais uma capacidade tal como o são os sentidos. Trata-se de algo simplesmente impossível de ser aprendido, porque nenhuma demonstração a partir dos conceitos consegue conduzir à aplicação de regras”. VM, p. 77 [36]. Como consequência disso, o juízo perderia sua referência ao universal, internalizando-se subjetivamente: “(...) deve-se observar nessa determinação do julgamento que aqui não é simplesmente aplicado um conceito pré-existente da coisa, mas que o sensorialindividual em si acaba chegando à apreensão, na medida em que se percebe nele a concordância do múltiplo no uno. O decisivo aqui, portanto, não é a aplicação de um universal, mas a concordância interna. (...) trata-se já daquilo que mais Kant mais tarde viria a denominar 'juízo reflexivo' e que entende como o julgamento segundo uma finalidade real e formal. Não se dá nenhum conceito, mas o individual é julgado 'imanente', Kant chama a isso um julgamento estético (...)”. VM, p. 77-78 [37].

8 “(...) no conceito de gosto (...) se desconhece o elemento ideal normativo, e se dá atenção ao raisonnement relativista-cético sobre a diversidade do gosto. (...) somos influenciados pelo desempenho moral-filosófico de Kant, que purificou a ética de todos os momentos estéticos e 
privilégio à figura do gênio no âmbito das ditas “belas artes”, ou seja, ao indivíduo que se coloca acima das regras pré-estabelecidas e se presta ao livre exercício da criatividade por meio de um jogo de forças imaginativas. ९ Tal concepção do fenômeno artístico implicaria o esvaziamento de seu conteúdo cognitivo e comunitário-social $\stackrel{\text { I0 }}{\square}$

A despeito dos acertos da estética kantiana, reconhecidos por Gadamer sobretudo sua emancipação do domínio de uma abordagem demonstrativam-,

sentimentais. (...) Limitou o conceito de gosto a campo em que podia reivindicar, como um princípio próprio do juízo, validade autônoma e independente - e, no lado oposto, restringiu com isso o conceito do conhecimento à utilização teórica e prática da razão. A intenção transcendental, que o guiava, encontrou sua realização no restrito fenômeno do julgamento sobre o belo (e o sublime) e desterrou do centro da filosofia o conceito mais universal da experiência do gosto e a atividade do juízo estético no âmbito do direito e dos costumes”. VM, p. 90-9I [46].

9 "A irracionalidade do gênio (...) torna apreensível um momento da criação produtiva de regras, que se mostra da mesma forma tanto a quem cria como a quem desfruta: face à obra da arte bela, não há nenhuma possibilidade de apossar-se de seu conteúdo, a não ser sob a forma única da obra e sob o mistério de sua impressão, que nenhuma linguagem jamais poderá alcançar inteiramente. O conceito do gênio coincide, pois, com o que Kant considera o decisivo do gosto estético, ou seja, o jogo aliviado das forças do ânimo, a ampliação do sentimento vital que se gera da congruência da forma de imaginação e entendimento e que convida ao repouso ante o belo. O gênio é um modo de manifestação desse espírito vivificador. Pois face à rígida regularidade da maestria escolar, o gênio mostra o livre impulso da invenção e, com isso, uma originalidade criadora de modelos”. VM, p. 107 [58-59].

Io "O que o conceito do gênio produz é pois apenas comparar esteticamente os produtos das belas artes com a beleza da natureza. Também a arte é vista esteticamente, isto é, também ela é um caso para o juízo reflexivo. O que é trazido à tona intencionalmente - e, nesse sentido, plenamente adequado ao fim - não deve ser relacionado a um conceito, mas pretende agradar, com relação ao mero julgamento - tal qual o belo natural. 'As belas artes são arte do gênio', não significa nada mais do que o seguinte: também para o belo. Não existe na arte nenhum outro princípio de julgamento, nenhuma medida de conceito ou de conhecimento, a não ser o da conveniência (Zweckmässigkeit) para o sentimento da liberdade no jogo de nossa capacidade de conhecimento. O belo na natureza ou na arte possui um e mesmo princípio apriorístico, que reside totalmente na subjetividade. A autonomia do juízo estético não fundamenta, de forma alguma, nenhum campo de validade autônoma para belos objetos. A reflexão transcendental de Kant sobre um a priori do juízo justifica a reivindicação do julgamento estético, mas, no fundo, não admite uma estética filosófica no sentido de uma filosofia da arte (...)”. VM, p. IIo [6I].

II "É claro que a validade do belo não se deixa derivar e comprovar a partir de um princípio universal. Ninguém duvida de que as questões de gosto não podem ser decididas através de ar- 
cabe questionar se a atitude crítica de uma fundamentação transcendental da razão, não produziria, quando aplicada à arte, uma consequência demasiado deletéria:

A função transcendental, que Kant atribui ao juízo estético, é bastante para satisfazer à delimitação contra o conhecimento conceitual e, como tal, à função dos fenômenos do belo e da arte. Mas a questão será a de salvaguardar o conceito da verdade do conhecimento conceitual? Não se tem também de reconhecer que a obra de arte tem uma verdade: $:^{12}$

Se Kant tinha razão, por um lado, ao situar a arte fora do domínio do método das ciências naturais, ele não teria razão, por outro lado, ao limitar o acesso à verdade - ou seja, sua cognoscibilidade - apenas àquilo que cairia sob esse mesmo domínio. Com efeito, um olhar retrospectivo sobre o alcance que tinham a tríade senso comum, juízo e gosto antes da reformulação transcendental kantiana parece apontar precisamente para o papel cognitivo e ético-moral da arte.

O que Gadamer encontra, ao resgatar a tradição humanística, é acima de tudo um modo de se relacionar com a verdade que se perdeu na modernidade, e mais especificamente com o advento do Esclarecimento: o saber prático da phronesis aristotélica, em oposição à sophia de orientação teorética ${ }^{13}{ }^{13}$ A atualização

gumentação e demonstração. Da mesma forma, é claro que o bom gosto jamais há de possuir uma real universalidade empírica, pois que o apelo ao gosto dominante ignora a genuína natureza do gosto. (...) não se deve submeter cegamente e nem simplesmente imitar a medianidade de padróes dominantes e de modelos selecionados. No âmbito do gosto estético, o modelo e a amostra têm, de fato, sua função preferencial, mas, como Kant diz corretamente, não na forma da imitação, mas do seguimento. $\mathrm{O}$ modelo e o exemplo dão ao gosto um indício para seguir o seu próprio caminho, mas não lhe retiram a tarefa própria”. VM, p. 93 [48].

${ }^{12}$ VM, p. 92 [47].

I3 “(...) aqui atua o antigo antagonismo aristotélico do saber prático e do teórico, um antagonismo que não se deixa reduzir ao antagonismo do que é verdadeiro e do que é provável. $\mathrm{O}$ saber prático, a phronesis, é uma outra forma de saber. De início, significa o seguinte: encontrase dirigida à situação concreta. Terá pois de abranger as circunstâncias em sua infinita variedade. (...) esse saber se subtrai ao conceito racional do saber. No entanto, e na verdade, não se trata de um mero ideal de resignação. $\mathrm{O}$ antagonismo aristotélico significa ainda algo bem diferente do 
humanista desse modo de acessar a verdade, com indissociável componente moral e social, indica o equívoco da pretensão moderna de purificar a cognição de tudo que não seja propriamente teórico. Nesse sentido, a vinculação a um só tempo ética, histórica e cognitiva das noçốes de senso comum. $\underbrace{14}$ juízq ${ }^{15}$ e gosto ${ }^{16}$ apresentam um desafio à redução da verdade apenas ao que seja apreensível por

que apenas o antagonismo entre o saber baseado em princípios universais e o saber do concreto. Também não significa a capacidade de subsunção do particular pelo universal, que denominamos 'força do juízo'. O que atua aí é, muito mais, um motivo ético, positivo (...). A compreensão e o domínio moral da situação concreta exigem uma tal subsunção do dado sob o universal, ou seja, o fim que se persegue para que daí resulte o correto. Pressupóe, portanto, um direcionamento da vontade, isto é, um ser moral (hexis). (...) Embora essa virtude, ao ser exercitada, faça com que se diferencie o factível do infactível, ela não é simplesmente uma inteligência prática e uma engenhosidade universal. O seu diferenciar entre o factível e o infactível abrange também a diferenciação entre o conveniente e o inconveniente e, assim, pressupóe uma atitude moral, que, por sua vez, aperfeiçoa-o”. VM, p. 64-65 [27].

I4 "sensus communis significa aqui, certamente, não somente aquela capacidade universal que existe em todos os homens, mas, ao mesmo tempo, o senso que institui comunidade. O que dá à vontade humana sua diretriz (...) não é a universalidade abstrata da razão, mas a universalidade concreta, que representa a comunidade de um grupo, de um povo, de uma nação, do conjunto da espécie humana. O desenvolvimento desse senso comum é, por isso, de decisiva importância para a vida”. VM, p. 63 [26].

Is "A 'sã compreensão humana', de vez em quando também denominada 'compreensão comum', é, de fato, caracterizada decisivamente pelo juízo. É isso que diferencia um tolo de uma pessoa inteligente: o fato de aquele não possuir nenhum juízo, isto é, o fato de não ser capaz de aplicar corretamente o que aprendeu e sabe. A introdução da palavra 'juízo', no século XVIII, quer, portanto, reproduzir adequadamente o conceito de indicium, que deveria valer como uma virtude espiritual fundamental. No mesmo sentido acentuavam os filósofos moralistas ingleses que o julgamento moral e estético não obedece à reason possuindo, porém, o caráter do sentimento (...)”. VM, p. $76[36]$.

16 "Sob o conceito de gosto pensa-se, sem dúvida, uma forma de conbecimento. Ocorre sob o signo do bom gosto que se seja capaz de manter distância quanto a si próprio e quanto às preferências privadas. O gosto não é, segundo sua natureza mais própria, nada que seja privado, mas, sim, um fenômeno social de primeira categoria. Pode até opor-se à inclinação privada do indivíduo, como se fosse uma instância de julgamento, em nome de uma universalidade, no que ele acredita e a que representa. Pode-se ter uma preferência por algo que o próprio gosto ao mesmo tempo repudia. A sentença judicial do gosto possui nisso uma peculiar decisão. Quanto a questóes de gosto não existe, reconhecidamente, nenhuma possibilidade de argumentar (...), mas não somente porque não se consegue estabelecer padróes conceituais universais, que todos tenham de reconhecer, mas porque nem sequer se procuram esses tais padróes (...). Gosto, a gente 
meio do paradigma epistêmico-metódico das ciências naturais. Para o que nos interessa aqui, o resgate da tradição humanista parece evidenciar a necessidade de se mobilizar uma abordagem estética capaz de reconhecer, de legitimar e de acessar a verdade da arte, tarefa para a qual a filosofia kantiana não estaria à altura.

\section{I.2 Os limites da vivência e da representação}

Quanto ao segundo movimento indicado no início desta seção - a abordagem fenomenológica da arte -, trata-se de examinar em que medida a estética pós-kantiana, em especial com a reformulação do conceito de gênio no idealismo alemã $q^{17}$ e a correspondente emergência da noção de vivência (Erlebnis) $:^{18}$ oferece

tem de ter - não se pode deixar que nos seja demonstrado, e também não se pode substituí-lo por mera imitação. Da mesma forma, o gosto não é nenhuma mera propriedade privada, porque ele quer ser bom gosto. A decisão do juízo do gosto inclui sua reivindicação de validade. $\mathrm{O}$ bom gosto está sempre seguro de seu julgamento, isto é, ele é, de acordo com sua natureza, um gosto seguro: um aceitar ou rejeitar que não conhece nenhuma oscilação, nenhum olhar de soslaio a um outro e nenhuma procura por motivos”. VM, p. 84 [4I-42].

17 "A redução de Kant do conceito de gênio ao artista (...) não conseguiu se impor. Ao contrário, no século XIX o conceito de gênio elevou-se a um conceito de valor universal e experimentou - em união com o conceito de criatividade - uma verdadeira apoteose. Era o conceito romântico-idealista da produção inconsciente, que suportou esse desenvolvimento e que alcançou uma enorme repercussão através de Schopenhauer e da filosofia do inconsciente. (...) a preocupação essencial de Kant veio a produzir uma fundamentação da estética que é autônoma e liberta do padrão do conceito, e de maneira alguma chegou a colocar a questão relativa à verdade no âmbito da arte, mas fundamentou o julgamento estético sobre o a priori subjetivo e do sentimento vital, a harmonia de nossa capacidade para 'o conhecimento como tal', que perfaz a essência comum do gosto e do gênio, anteposto ao irracionalismo e ao culto do gênio do século XIX. A doutrina de Kant sobre a 'elevação do sentimento vital' no prazer estético promoveu o desenvolvimento do conceito 'gênio' para um conceito de vida abrangente, principalmente depois que Fichte havia elevado o ponto de vista do gênio e a produção genial a um ponto de vista universal e transcendental”. VM, p. II6-II7 [65].

${ }^{18}$ Gadamer lista dois sentidos para o termo: I "Vivenciar significa, de início, 'ainda estar vivo, quando algo acontece'. A partir daí, a palavra 'vivenciar' passa a carregar o tom da imediaticidade com que se abrange algo real - ao contrário daquilo que se pensa saber, mas para o qual falta a credencial da vivência própria, quer o tenhamos recebido de outros, ou venha do ouvir falar, quer o tenhamos deduzido, intuído (gemutmasst). O vivenciado (das Erlebte) é sempre o que nós mesmos vivenciamos (das Selbsterlebte)"; 2 "Ao mesmo tempo, porém, a forma 'o viven- 
uma alternativa satisfatória e dá conta da verdade veiculada por fenômenos artísticos. Com efeito, a primazia do gênio como instância de produção do sentido e da verdade artísticos ensejou a construção do paradigma interpretativo que coloca a compreensão da vida do autor - do gênio - como guia da interpretação da obra, numa virada biografista ${ }^{19}$

A despeito da pertinência da vinculação entre "vivência" e "arte" - ou "consciência estética" - ${ }^{20}$ Gadamer aponta para três limitações fundamentais desse conceito, que o desabonam em sua pretensão de dar conta da experiência artística: I. o conceito de "vivência" surge, tanto em sua formulação hermenêutica quanto em sua formulação fenomenológica, como ferramenta epistêmica na busca por uma fundamentação metódica $\left\lfloor^{21}\right.$ o que significa que embora leve vantagem sobre

ciado' é usada no sentido de que o conteúdo duradouro daquilo que é vivenciado receberá daí sua designação. Esse conteúdo é como um rendimento ou resultado que, da transitoriedade do vivenciar, ganha duração, peso e importância”. VM, p. II8 [66-67].

19 "a partir da vida, se compreende a obra. (...) Algo se transforma em vivência na medida em que não somente foi vivenciado, mas que o seu ser-vivenciado tem uma ênfase especial, que lhe empresta um significado duradouro. O que, dessa maneira, vem a ser uma 'vivência' ganha um status de ser totalmente novo na expressão da arte. (...) De fato, foi Dilthey quem primeiro atribuiu a essa palavra uma função conceitual (...)”. VM, p. IIs [67].

20 "A experiência estética não é apenas uma espécie de vivência ao lado de outras, mas representa a forma de ser da própria vivência. Como a obra de arte, como tal, é um mundo para si, assim o vivenciado esteticamente, como vivência, distancia-se de todas as correlaçóes com a realidade. Parece, por assim dizer, que a determinação da obra de arte é a de se tornar uma vivência estética; ou seja, que arranque a um golpe aquele que a vive, do conjunto de sua vida, por força da obra de arte e que, não obstante, volte a referi-lo ao todo de sua existência. Na vivência da arte há presente uma pletora de significados que não somente pertence a este conteúdo específico ou a esse objeto, mas que, antes, representa o todo do sentido da vida. Uma vivência estética contém sempre a experiência de um todo infinito. E seu significado é infinito justamente porque não se conecta com outras coisas para a unidade de um processo aberto de experiência, já que representa o todo imediatamente”. VM, p. I3I [75-76].

${ }_{21}$ “(...) em Dilthey, como em Husserl, na filosofia da vida, tal como na fenomenologia, o conceito de vivência se mostra, de início, como um conceito puramente epistemológico. Em ambos ele é reivindicado com a sua significação teleológica, mas não é determinado conceitualmente. Que é a vida que se manifesta na vivência, significa apenas que é a última coisa a que tornamos a voltar. (...) O que vale como uma vivência não é mais meramente uma fugaz torrente passageira na torrente da vida consciente - é vista como unidade e ganha, através disso, uma nova maneira de ser uma”. VM, p. 126 [72]. 
a situação da estética kantiana ao reabilitar a dimensão cognitiva da experiência artística, ainda assim permanece enredado no reducionismo da verdade da arte a uma abordagem à moda das ciências, reiterando seu esvaziamento moral e não dando conta de sua dimensão de saber prático; 2. as formulaçóes desse conceito em estética parece tomar como paradigma manifestações artísticas tipicamente surgidas nos séculos XVIII e XIX, se revelando inadequado à tentativa de compreensão de fenômenos artísticos de outra época e, com isso, evidenciando um déficit historiográfico, ${ }^{22}$ o que se torna ainda mais explícito quando se examina o papel do símbolo e da alegoria na arte de outras épocas ${ }^{23} 3$. a concepção da criação artística como representação da vivência do gênio - que, lembremos, se move pelo livre exercício de suas forças imaginativas - provoca ruptura com a realidade, separando o gênio de seu contexto e de sua comunidade ${ }^{24}$ e situando a

22 "O conceito da arte vivencial somente se torna consciente na sua circunscrição, quando deixa de ser auto-evidente que uma obra de arte represente uma transposição de vivências, e quando já não é auto-evidente que essa transposição se deve à vivência de uma inspiração genial que, por sua vez, converter-se-á numa vivência para aquele que a recebe. Para nós, o século caracterizado pela auto-evidência desses pressupostos é o de Goethe, um século que é toda uma era, uma época. Somente porque para nós já está encerrado, e porque isso nos permite ver além de seus limites, podemos vê-lo nos seus limites e para isso temos um conceito". VM, p. I32 [76].

23 "A sólida situação prévia (Vorfindlichkeit) da contraposição do conceito: o símbolo que cresce 'organicamente' - a alegoria fria e adequada à compreensão perde seu caráter obrigatório, quando se reconhece sua vinculação com a estética do gênio e com a estética da vivência. (...) $\mathrm{O}$ fundamento da estética do século XIX foi a liberdade da atividade simbólica da índole (Gemüt). Mas será que essa é uma base sustentável? Será que, na verdade, essa atividade simbólica não está sendo limitada ainda hoje pela sobrevivência de uma tradição mítico-alegórica? Quando se reconhece isso, o antagonismo de símbolo e alegoria tem de se relativizar de novo, embora, sob o preconceito da estética experimental, parecesse absoluto. Da mesma forma, a diferença entre a consciência estética e a mítica mal conseguirá se fazer valer como um absoluto”. VM, p. 146 [87].

24 “(...) através da 'diferenciação estética', a obra perde o seu lugar e o mundo a que pertence por se tornar parte integrante da consciência estética. (...) também o artista perde seu lugar no mundo. (...) Na consciência pública dominada pela época da arte vivencial, (...) a criação ocorria por inspiração livre, sem encomenda, sem tema predeterminado, sem uma oportunidade dada (...). O artista livre cria sem receber encomenda. Parece que o que o caracteriza é a completa independência de seu trabalho criativo, o que, por isso, lhe confere, mesmo socialmente, as feiçôes características de um excêntrico, cujas formas de vida não podem ser mensuradas de acordo com as massas que obedecem aos costumes públicos”. VM, p. 155-156 [93]. 
verdade da obra no domínio da representação teórica. ${ }^{25}$

Face a essas aporias da consciência estética, caberia, segundo Gadamer, reconduzir o fenômeno artístico a seu contexto de produção e emergência, de modo a reintegrar na analítica da verdade de seu conteúdo a dimensão histórica que havia se perdido na reformulação iluminista e romântica dos conceitos humanísticos de senso comum, juízo e gosto, como vimos. Com efeito, Gadamer opõe à "diferenciação estética” e à formação de uma consciência estética autônoma e fechada em si mesma uma perspectiva informada pela história da arte, da qual emergirá uma concepção de arte como experiência:

O panteão da arte não é uma atualidade independente do tempo, que se apresenta à pura consciência estética, mas o fato de um espírito histórico que se concentra e se congrega. Também a experiência estética é uma forma de compreender-se. Todo compreender-se se completa, porém, em algo diferente do que aí se compreende, e inclui a unidade e a mesmidade desse diferente. Uma vez que encontramos no mundo a obra de arte e em cada obra de arte individual um mundo, este não continua a ser um universo estranho em que, por encantamento, estamos à mercê do tempo e do momento. Nele, mais do que isso, aprendemos a nos compreender, e isso significa que suspendemos a descontinuidade e a pontualidade da vivência na continuidade da nossa existência. O que importa, por isso, é chegar a um ponto de partida, com relação ao belo e à arte que não pretenda a imediaticidade, mas que corresponda à realidade histórica do homem. A invocação à imediaticidade, ao que for genial no momento, ao significado da "vivência", não poderá resistir à reivindicação da existência humana à continuidade e à unidade do que é

25 "O que chamamos de obra de arte e vivenciamos esteticamente repousa, portanto, sobre um desempenho de abstração. Na medida em que não se leva em consideração tudo em que uma obra se enraíza, como seu contexto de vida originário, isto é, toda função religiosa ou profana em que se encontrava e em que possuía seu significado, é aí que se tornará visível a 'pura obra de arte'. A abstração da consciência estética produz, nesse particular, um desempenho que é, para si mesma, positivo. Permite ver e ser para si próprio aquilo que é a pura obra de arte. Denomino esse seu desempenho a 'diferenciação estética'.” VM, p. I52 [91]. 
auto-evidente. A experiência da arte não poderá ser comprimida no descomprometimento da consciência estética. ${ }^{26}$

A virada histórica - que não se confunde com o historicismo (criticado na segunda parte de Verdade e método) - imposta à consciência estética é o que permite retomar a dimensão propriamente cognitiva do fenômeno artístico e a correspondente pergunta por sua fundamentação. Na síntese de Gadamer: "a arte é conhecimento e a experiência da obra de arte torna esse conhecimento partilhável. Com isso se coloca a pergunta de como se poderá fazer jus à verdade da experiência estética e de como suplantar a radical subjetivação do estético, que teve início com (...) Kant" ${ }^{27}$

Ao preconizar a realização desse gesto, Gadamer se volta à filosofia hegeliana como exemplo histórico dessa tarefa ${ }^{28}$ Hegel teria, na leitura de Gadamer, reconduzido os fenômenos artísticos a seu aparecer histórico e, com isso, reabilitado seu conteúdo próprio de verdade: não a verdade científica, estruturada por procedimentos metódicos, mas a verdade "tal qual se faz visível no espelho da arte". Contudo, a despeito da superação do subjetivismo estético e da retomada de seu conteúdo de conhecimento, Hegel não teria sido capaz - sempre segundo Gadamer - de fazer jus a seu caráter experiencial, à dimensão eminentemente prática do saber que a arte veicula, e isso por subsumi-la à verdade conceitual teórico-filosófica; para dar conta da experiência, seria preciso, em vez de reconduzir o conjunto variado de fenômenos a uma unidade conceitual, assumir, ao contrário, a variabilidade como característica imanente do tipo de saber e verdade contidos nesses fenômenos 29

${ }^{26}$ VM, p. I68-169 [IO2-IO3].

${ }^{27}$ VM, p. 169 [103].

28 “Com relação a essa tarefa, podemos nos reportar às admiráveis preleções de Hegel sobre a estética. Nelas, de uma forma extraordinária, o conteúdo de verdade que há em toda experiência da arte é trazido ao reconhecimento e, ao mesmo tempo, transmitido com consciência histórica. Com isso, a estética torna-se uma história das cosmovisóes, isto é, uma história da verdade, tal qual se faz visível no espelho da arte. Com isso, confirma-se fundamentalmente a tarefa (...) de justificar na própria experiência da arte o conhecimento da verdade”. VM, p. I70 [I03].

29 "É verdade que Hegel só conseguiu reconhecer a verdade da arte devido ao fato de tê-la sobrepujado com o saber conceitual da filosofia, e construiu a história das cosmovisóes, bem 


\section{I.3 Análise ontológica da experiência da arte}

Compreender a experiência da arte como experiência de verdade e de sentido, tal é a tarefa que se impóe se quisermos dar conta, a um só tempo, do conteúdo de verdade da arte e de seu caráter prático. As tentativas de desenvolvimento da consciência estética face ao diagnóstico da insuficiência e da inadequação do método das ciências naturais, tanto em sua vertente crítica kantiana quanto em sua vertente romântico-idealista, não se provaram à altura da exigência em questão.

Gadamer se volta, portanto, à herança fenomenológico-hermenêutica, na esteira de Heidegger, para elaborar a compreensão adequada das obras de arte. Nessa perspectiva, a experiência com a obra de arte aparece como um acontecimento:

O que nos importa, portanto, é ver a experiência da arte de tal maneira que venha a ser entendida como experiência. A experiência da arte não deve ser falsificada como um fragmento da formação estética que está na sua posse e, com isso, não deve ter neutralizada sua reivindicação própria. (...) nisso reside uma consequência hermenêutica de longo alcance, na medida em que todo encontro com a linguagem da arte éum encontro com um acontecimento não acabado e, ela mesma, uma parte desse acontecimento. É a isso que se tem de pôr em relevo contra a consciência estética e contra a sua neutralização da questão da verdade ${ }^{30}$

como a história mundial e a história da filosofia, a partir de uma completa autoconsciência do presente. (...) É verdade que, na medida em que a verdade do conceito, através disso, se torna todo-poderosa e suspende em si toda experiência, a filosofia de Hegel desautoriza, ao mesmo tempo e novamente, o caminho da verdade, que reconhecera na experiência da arte. Se procurarmos defender esse caminho no que lhe cabe de razão, teremos de prestar conta, por princípio, ao que, aqui, se chama de verdade. São as ciências do espírito no seu conjunto onde se terá de ir encontrar uma resposta para essa pergunta. Pois estas não querem suplantar, mas compreender a variabilidade de todas as experiências, quer seja variabilidade da consciência estética ou histórica, quer a da consciência religiosa ou política, o que, porém, significa: exceder-se em sua verdade". VM, p. I70-I7I [IO4].

${ }^{30}$ VM, p. I7I [104-IO5]. 
Tomar a obra de arte como acontecimento, e concebê-lo como acontecimento aberto, do qual a experiência do encontro com essa obra faz parte, tudo isso aponta para o deslocamento de uma dimensão fundamental do modo de ser desse acontecimento, a saber sua dimensão temporal. Pois não se trata mais apenas de historicizar a emergência e a produção do fenômeno, ou a vida do artista que a cria, mas também a experiência de sua recepção. Com isso, a simultaneidade abstrata que caracterizava a consciência estética ${ }^{37}$ se desestabiliza e se transforma em abordagem da temporalidade como dimensão ontológica, situando o intérprete - e, consequentemente, a compreensão - numa relação a um só tempo de distância e de vinculação com aquilo que é compreendido $3^{22}$

Consequentemente, a verdade da arte se produz, se desdobra e se apreende no tempo. Dado que as tentativas de compreender essa verdade a compóem, como parte de seu acontecimento, as condições temporais do intérprete entram em jogo com as condiçóes temporais do aparecer da obra. É por isso que Gadamer se concentrará sobre a estrutura da pré-compreensão, que deixam de ser restos de irracionalidade ou irreflexão que obstaculizam a interpretação verdadeira, revelando-se, ao contrário, como condiçôes (ontológicas) de possibilidade

3I “(...) a consciência estética tem o caráter da simultaneidade, por reivindicar que nela se congregue tudo o que tem valor de arte. A forma de reflexão em que ela se movimenta, enquanto estética, bem por isso, não é somente uma forma presente. Pois na medida em que a consciência estética eleva em si à simultaneidade, tudo a que empresta validade determina a si mesma ao mesmo tempo como uma consciência histórica. Não somente por incluir o conhecimento histórico, e por utilizá-lo como sinal distintivo - a dissolução de todo gosto que tem determinação de conteúdo, e que lhe é próprio, do ponto de vista estético, mostra-se também expressamente, na criação do artista, na conversão em algo histórico. A imagem da história, que não deve sua origem a uma necessidade de representação (Darstellung) contemporânea, mas sim à representation a partir da reflexão retroativa histórica (...), tudo isso mostra a pertença íntima dos momentos estético e histórico na consciência da formação”. VM, p. I53-I54 [9I-92].

32 "A interpretação do ser, a partir do horizonte do tempo, não significa (...) que o ser-aí seja temporalizado tão radicalmente que já não possa mais deixar valer nada como sempre-sendo ou como eterno, mas que deve compreender-se totalmente com relação ao seu próprio tempo e futuro. (...) A questão da filosofia é indagar o que vem a ser o cume do compreender-se. Com essa indagação, ultrapassam, em princípio, o horizonte desse compreender-se. Ao revelar o tempo como o seu fundamento oculto, não prega um engajamento cego com base num desespero niilista, mas abre-se a algo até então oculto, a uma experiência que supera o pensamento baseado na subjetividade, que Heidegger denomina de ser”. VM, p. I72 [IO5]. 
da compreensão ela mesma. Não se trata nem de suspender pré-conceitos ou enraizamento cultural numa tradição, submetendo-os a crítica, nem de deslocar-se temporalmente para o horizonte vivencial do autor e da obra, mas de integrar a diacronia temporal como o que possibilita a interpretação, como o que permite que a obra faça sentido, como o que também constitui esse sentido.

Não podendo me aprofundar na maneira como Gadamer esboça os traços fundamentais disso a que ele chamará "consciência hermenêutica", proponho apenas que examinemos uma objeção que lhe foi oposta, concernindo especificamente a compreensão de fenômenos artísticos. Trata-se da crítica formulada por Hans Robert Jauss, um dos proponentes da chamada "estética da recepção". Mostrarei como Jauss se apropria da temporalização da compreensão em Gadamer - em especial, da noção de "horizonte de interpretação" - para criticar sua hermenêutica e dar outro direcionamento à estética, na tentativa de resgatar - ou salvar - sua pretensão à fundamentação epistemológica ${ }^{3}$

\section{Diacronia e pluralidade de horizontes de recepção como epistemologia estética}

Um ponto de partida para situar a oposição entre Gadamer e Jauss talvez seja a relação entre estética e história. ${ }^{34}$ Ambos os autores se mostram conscientes e sensíveis à dimensão historiográfica da interpretação de fenômenos artísticos. Tomando como objeto a literatura - e seus desdobramentos em crítica literária e história da literatura -, Jauss coloca essa tarefa - a de ligar a dimensão estética à dimensão histórica - a partir das insuficiências das concepções marxista e formalista para lidar com essa tensão, erigindo como eixo articulador precisamente o ponto de vista do leitor-intérprete - tema, como vimos, caro também a Gadamer:

(...) eu vejo o desafio da crítica literária na retomada do problema da história da literatura deixado em aberto pela disputa entre o

33 Para outra perspectiva sobre o impacto da estética gadameriana, ver: Ramírez Cobián, Mario. "O legado estético de Gadamer”. In: Princípios, v. 19, n.3I (2012), pp. 53-64.

${ }^{34}$ Alternativamente, ver: Haidu, Peter. "The semiotics of aterity: A comparison with hermeneutics”. In: New Literary History, v. 2I, n. 3, primavera, 1990, pp. 67I-69I. 
método marxista e o formalista. Minha tentativa de superar o abismo entre literatura e história, entre o conhecimento histórico e estético pode, pois, principiar do ponto em que ambas as escolas pararam. Seus métodos compreendem o fato literário encerrado no círculo fechado de uma estética da produção e da representação. Com isso, ambas privam a literatura de uma dimensão que é componente imprescindível tanto de seu caráter estético quanto de sua função social: a dimensão de sua recepção e de seu efeito. Leitores, ouvintes, espectadores - o fator público, em suma, desempenha naquelas duas teorias literárias um papel extremamente limitado 35

A intuição inicial de Jauss $3^{36}$ é bastante simples: uma vez que obras literárias são escritas para serem lidas, e que essas leituras se espalham - e se distanciam na história, no tempo, então o ponto de vista do leitor é, ele também, constitutivo desse fenômeno artístico - para falarmos uma vez mais com Gadamer. Jauss desdobra as consequências do enfoque na recepção em ambas as dimensóes, estética e histórica:

Considerando-se que, tanto em seu caráter artístico quanto em sua historicidade, a obra literária é condicionada primordialmente pela relação dialógica entre literatura e leitor - relação que pode ser entendida tanto como aquela da comunicação (informação) com o receptor quanto como uma relação de pergunta e resposta -, há de ser possível, no âmbito de uma história da literatura, embasar nessa mesma relação o nexo entre as obras literárias. E isso porque a relação entre literatura e leitor possui implicaçôes tanto estéticas quanto históricas. A implicação estética reside no fato de já a recepção primária de uma obra pelo leitor encerrar uma avaliação de seu valor estético, pela comparação com outras obras já lidas. A implicação histórica manifesta-se na possibilidade de, numa cadeia

${ }^{35}$ Jauss, Hans Robert. A bistória da literatura como provocação à teoria literária. São Paulo: Ática, I994, p. 22.

${ }^{36}$ Para uma introdução, ver: Figurelli, Roberto. "Hans Robert Jauss e a estética da recepção”. Letras, v. 37 (1988), pp. 265-285. 
de recepções, a compreensão dos primeiros leitores ter continuidade e enriquecer-se de geração em geração, decidindo, assim, o próprio significado histórico de uma obra e tornando visível sua qualidade estética. Se, pois, se contempla a literatura na dimensão de sua recepção e de seu efeito, então a oposição entre seu aspecto estético e seu aspecto histórico vê-se constantemente mediada, e reatado o fio que liga o fenômeno passado à experiência presente (...), fio este que o historicismo rompera 3

Numa primeira leitura, tem-se a impressão de que Jauss incorpora o argumento central de Gadamer: a experiência do encontro com a obra de arte - em Jauss, de sua recepção - é parte constitutiva de seu sentido, que se revela e se constrói ao longo do tempo. Entretanto, o projeto de Jauss não poderia ser mais incompatível com a hermenêutica gadameriana: trata-se ainda, para aquele, de buscar uma fundamentação metodológica para a crítica literária e a história da literatura no conceito de "horizonte de recepção" ${ }^{8}$

Jauss reconhece, assim como Gadamer, a dimensão histórica do modo de ser da obra de arte ${ }^{39}$ dá, contudo, um passo além dele, ao vislumbrar a "possibilidade de objetivação” da diacronia produção-recepção das obras de arte:

(...) na ausência de sinais explícitos, a predisposição específica do público com a qual um autor conta para determinada obra pode ser

${ }^{37}$ Jauss, Hans Robert. A história da literatura como provocação à teoria literária. São Paulo: Ática, 1994, p. 23.

38 "Com base nessa premissa, cumpre agora responder à pergunta acerca de como se poderia hoje fundamentar metodologicamente e reescrever a história da literatura”. Id., p. 23.

39 "A obra literária não é um objeto que exista por si só, oferecendo a cada observador em cada época um mesmo aspecto. Não se trata de um monumento a revelar monologicamente seu Ser atemporal. Ela é, antes, como uma partitura voltada para a ressonância sempre renovada da leitura, libertando o texto da matéria das palavras e conferindo-lhe existência atual (...). É esse caráter dialógico da obra literária que explica por que razão o saber filológico pode apenas consistir na continuada confrontação com o texto, não devendo congelar-se num saber acerca de fatos. $\mathrm{O}$ saber filológico permanece sempre vinculado à interpretação, e esta precisa ter por meta, paralelamente ao conhecimento de seu objeto, refletir e descrever a consumação desse conhecimento como momento de uma nova compreensão". Id., p. 25. 
igualmente obtida a partir de três fatores (...): em primeiro lugar, a partir de normas conhecidas ou da poética imanente ao gênero; em segundo, da relação implícita com obras conhecidas do contexto histórico-literário; e, em terceiro lugar, da oposição entre ficção e realidade, entre a função poética e a função prática da linguagem, oposição esta que, para o leitor que reflete, faz-se sempre presente durante a leitura, como possibilidade de comparação. Esse terceiro fator inclui ainda a possibilidade de o leitor perceber uma nova obra tanto a partir do horizonte mais restrito de sua expectativa literária, quanto do horizonte mais amplo de sua experiência de vida 40

A partir desses elementos do horizonte de recepção, Jauss se vê capaz de determinar e julgar o valor estético de uma obra literária: quanto mais perturbações, inquietações e transformações uma obra produz no público receptor, tanto maior seu valor estético. ${ }^{41} \mathrm{Tal}$ juízo só se faz possível, em sua perspectiva, pois ele crê ter atingido o domínio epistemológico da distância temporal, o que lhe permite reconstruir horizontes de expectativa e de recepção passados e integrá-los - como conhecimento determinado - ao horizonte presente ${ }^{\sqrt{2}}$

$4^{\circ 0}$ Id., pp. 29-30.

41 "A maneira pela qual uma obra literária, no momento histórico de sua aparição, atende, supera, decepciona ou contraria as expectativas de seu público inicial oferece-nos claramente um critério para a determinação de seu valor estético. A distância entre o horizonte de expectativa e a obra, entre o já conhecido da experiência estética anterior e a 'mudança de horizonte' exigida pela acolhida à nova obra, determina, do ponto de vista da estética da recepção, o caráter artístico de uma obra literária. À medida que essa distância se reduz, que não se demanda da consciência receptora nenhuma guinada rumo ao horizonte da experiência ainda desconhecida, a obra se aproxima da esfera da arte 'culinária' ou ligeira. (...) Se (...) trata-se de avaliar o caráter artístico de uma obra pela distância estética que a opõe à expectativa de seu público inicial, segue-se daí que tal distância - experimentada de início com prazer ou estranhamento, na qualidade de uma nova forma de percepção - poderá desaparecer para leitores posteriores, quando a negatividade original da obra houver se transformado em obviedade e, daí em diante, adentrando ela própria, na qualidade de uma expectativa familiar, o horizonte da experiência estética futura”. Id., pp. 3I-32.

42 "A reconstrução do horizonte de expectativa sob o qual uma obra foi criada e recebida no passado possibilita (...) que se apresentem as questóes para as quais o texto constituiu uma 
Jauss concebe a tarefa reconstrutiva e integrativa que guia a estética da recepção como incorporação do conceito hermenêutico (gadameriano) de horizonte de compreensão e sua elevação a autoconsciência metodológica: é esse conceito que permite ao teórico literário fundamentar epistemologicamente seus procedimentos comparatistas, sendo a consciência do papel da pré-compreensão nas atividades corriqueiras do interpretar e do comparar o traço distintivo da cientificidade dessas operaçóes ${ }^{43}$ Enfatizando o papel do jogo da questão e da resposta como condição de possibilidade da fundamentação do horizonte de compreensão ${ }^{44}$ e consciente do caráter histórico e variável das questôes face às quais uma

resposta e que se descortine, assim, a maneira pela qual o leitor de outrora terá encarado e compreendido a obra. Tal abordagem corrige as normas de uma compreensão clássica ou modernizante da arte - em geral aplicadas inconscientemente - e evita o círculo vicioso do recurso a um genérico espírito de época. Além disso, traz à luz a diferença hermenêutica entre a compreensão passada e a presente de uma obra, dá a conhecer a história de sua recepção - que intermedeia ambas as posições - e coloca em questão, como um dogma platonizante da metafísica filológica, a aparente obviedade segundo a qual a poesia encontra-se atemporalmente presente no texto literário, e seu significado objetivo, cunhado de forma definitiva, eterna e imediatamente acessível ao intérprete”. Id., p. 35 .

43 "How can a discipline lay claim to independence when its methodological procedure belongs to everyday practice of many scholarly activities? The learned humanist who reconstructs an event of the past from many sources; the linguist who investigates the structure of a language via contrast or from various states of the language; the jurist who draws on a precedent to solve a question of law: all work comparatively now and then, without seeing there an ultimate methodological principle. Only the professional comparatist seems to have forgotten that something more than the mere comparison belongs to the methodological application of comparison. For even the most highly developed practice of comparison tells us neither what should enter into the comparison (and what not), nor to what end. The relevance and thereby the selection of the comparison cannot be drawn directly from the compared elements themselves; even when in the end significance apparently 'springs out' on its own, it nonetheless presupposes hermeneutically a preconception [Vorgriff], however often unadmitted”. Jauss, Hans Robert. Toward an aesthetics of reception. Minneapolis: University of Minnesota Press, 1982, p. IIO.

44 " $(. .$.$) the comparative principle becomes reasoned to the degree that one brings to cons-$ ciousness the question or series of questions that orients each controlled comparison. This preliminary question, often unanswered by the objectivism of the philological operation, can be more or less relevant. (...) But the argument may adjust itself toward the actual matter at hand when the question that the interpreter poses to the text is confirmed as a question relevant to the meaning of the text through the hermeneutic process of question and answer. (...) At the end 
obra deve ser interpretada. ${ }_{45}^{45}$ Jauss procura incluir como critério de ponderação do questionar o próprio horizonte da obra, em seu confronto constantemente re-atualizado com o presente ${ }^{46}$

Com base nesse solo metodológico, Jauss pretende discernir - sempre metodologicamente - três estágios de interpretação, que acabam se confundindo na experiência prática do interpretar: perceptual-imediato, exegético-reflexivo e histórico-efeitual. ${ }^{47}$ Uma tal separação se fundamenta - ou ao menos é o que supõe Jauss - na articulação de três categorias do processo hermenêutico: compreender (intelligere), interpretar (interpretare) e aplicar (applicare) $:^{48} \operatorname{articulação~}$

of the whole series of question and answer it remains to be examined whether it has satisfied the latest interpreter, or rather leaves new problems unanswered”. Id., p. II3.

45 "Here one must warn against a second substantialist illusion. Whoever has escaped from the illusion of the timeless comparison may still run the danger of falling into the illusion of the timeless question. The literary work and, to an even greater degree, the literary myth have the character of an answer, the conclusiveness of which can cover over or cause one to forget the original question, so that it must be inferred in an ever-changing form in the process of the interpretations." Id., p. II3.

46 "Hermeneutic reflection cannot and need not deny the horizon of contemporary interests that continually co-conditions the kind and manner of questioning, even if the selection and sequence of question and answer must be corrected and decided from the perspective of the object of investigation”. Id., p. 137.

47 “(...) to distinguish methodologically into three stages of interpretation that which normally remains undistinguished in the interpretive practice of philological commentary as well as textual analysis. If it is the case there that understanding and interpretation as well as immediate reception and reflective exegesis of a literary text are at once blended in the course of interpretation, then the horizon of a first, aesthetically perceptual reading will be distinguished from that of a second, retrospective interpretive reading. To this I will add a third, historical reading that begins with the reconstruction of the horizon of expectation (...), and that then will follow the history of its reception or 'readings' up to the most recent (...)". Id., p. I39.

48 "The three steps of my interpretation (...) are grounded in the theory that the hermeneutic process is to be conceived as a unity of the three moments of understanding (intelligere), interpretation (interpretare), and application (applicare). (...) This uniy has determined, in a manner more or less one-sidedly realized, all textual interpretation from time immemorial; it was explicitly formulated by pietistic hermeneutics during the Enlightenment as the doctrine of the three subtilitates (...). The obvious backwardness of literary hermeneutics is explainable by the fact that here the hermeneutic process reduces to interpretation alone, that no theory of understanding has been developed for texts of an aesthetic character, and that the question 
esta que se pretende descrever fenomenologicamente - aqui, de maneira contrafactual - como uma sucessão virtual de três leituras, onde cada uma das operaçôes seria enfatizada. Tal artifício narrativo teria a finalidade didática de proporcionar clareza metódica à análise de uma obra literária 49

A descrição fenomenológica dessas três leituras se dá, em Jauss, da seguinte maneira: num primeiro momento, o leitor - que ignora a totalidade do texto com acaba de se deparar - vai percebendo parte a parte a obra - frase a frase, verso a verso, etc. - e antecipa a unidade da forma do fenômeno artístico em tela, embora permaneça incapaz de antecipar a realização de seu significado, até o ponto em que hipostasia em sentido singular um sentido performático, dentre diversas possibilidades de significação, que lhe parece mais relevante; em seguida, o leitor se volta retrospectiva e reflexivamente sobre o texto, buscando preencher seu sentido por meio de uma nova leitura, já tendo se apropriado perceptivamente de sua forma e respondendo às questôes que emergiram e ficaram em aberto quando da primeira leitura e interpretando o texto como unidade de sentido, a partir de uma afirmação seletiva, de um vir à consciência de seu horizonte de leitura e recepção: ${ }^{50}$ com isto, emerge a questão do horizonte histórico da obra, que se põe no centro da terceira leitura, confrontando sua própria interpretação com a

of 'application' has been relegated to book reviewers' criticism as an unscholarly one”. Id., pp. I39-I40.

49 "To find a methodological starting-point capable of further development, it was for me above all a matter of separating more sharply than has been done before the levels of aesthetic perception and reflective interpretation (...). An initial methodological advance may already result from this separation, namely that with the help of the question-answer relationship, the textual signals may now be specified within their syntagmatic coherence as the givens of the course of reception that establish consistency”. Id., p. I44.

so "(...) the reader - who performs the 'score' of the text in the course of the reception of verse after verse, and who is led toward the ending in a perceptual act of anticipation, from the particular toward the possible whole of form and meaning - becomes aware of the fulfilled form of the poem, but not yet of its fulfilled significance, let alone of its 'whole meaning'. Whoever acknowledges the hermeneutic premise that the meaningful whole of a lyric work is no longer to be understood as if substantial, as if its meaning were pregiven and timeless; rather, it is to be understood as a meaning to be performed - whoever acknowledges this premise awaits from the reader the recognition that from now on he may, in the act of interpretive understanding, hypostasize one among other possible significations of the poem, the relevance of which for him does not exclude the worth of others for discussion. From now on, the reader will seek and establish 
distância histórico-genealógica da obra e revelando preconceitos temporais que se impuseram na segunda leitura, a partir da tensão entre o horizonte presente da recepção e o horizonte pretérito da produção da obra ${ }^{1}$

Como dito acima, essa descrição não tem pretensão empírica; trata-se, antes, de uma análise contrafactual que permitiria, para Jauss, revelar as dimensóes que se entrelaçam no ato concreto da leitura, da recepção. Contudo, se compreensão, interpretação e aplicação intervêm simultaneamente na leitura, essas operaçóes aparecem, segundo Jauss, direcionadas por um privilégio sensível: o da percepção estético-sensorial. Isso porque o primeiro contato com o texto, a primeira impressão que vai se formando à medida que a leitura avança, se impóe como horizonte sobre toda interpretação. Essa sensibilidade perceptual, historicamente condicionada, fornece o solo epistemológico sobre o qual Jauss erige sua estética da recepção, a partir do qual se pode inclusive repensar o momento hermenêutico da aplicação sem os constrangimentos limitantes da tomada de decisão. ${ }^{22}$

the still unfulfilled significance retrospectively, through a new reading, from the perspective of the fulfilled form, in a return from the end to the beginning, from the whole to the particular. Whatever initially resisted understanding manifests itself in the questions that the first goingthrough has left open. In answering them, one may expect that from the particular elements of significance (...) a fulfilled whole may be established on the level of meaning as on the level of form. This meaningful whole can be found only through a selective taking of perspectives and cannot be attained through a supposedly objective description - this falls under the hermeneutic premise of partiality.” Id., p. 145-146.

5I "This third step, insofar as it concerns the interpretation of a work from the premises of its time and genesis, is the one most familiar to historical-philological hermeneutics. (...) aesthetic understanding and interpretation also remain in reference to the controlling function of historicist-reconstructive reading. It prevents the text from the past from being naively assimilated to the prejudices and expectations of meaning of the present, and thereby - through explicitly distinguishing the past horizon from the resent - allows the poetic text to be seen in its alterity. The investigation of the 'otherness', the unique distance, within the contemporaneity of the literary text, demands a reconstructive reading that can begin by seeking out the questions $(\ldots)$ to which the text was the response in its time. An interpretation of a literary text as a response should include two things: its response to expectations of a formal kind, such as the literary tradition prescribed for it before its appearance; and it response to questions of meaning such as they could have posed themselves within the historical life-world of is first readers". Id., p. 146 .

52 "The priority of aesthetic perception within the triad of literary hermeneutics has need 
É patente a pretensão epistemológica de Jauss. Para ele, tratava-se de reabilitar a dimensão cognitiva da experiência estética, a partir de uma integração da historicidade da interpretação na recepção. Se esse intento parece convergir com a análise gadameriana da consciência estética, há entre ambos divergências insuperáveis. Jauss identifica em Gadamer uma hipostasia indevida do conceito de clássico, 33 um paradigma que não faria sentido para produções anteriores à modernidade e que colocaria em risco o que haveria de melhor em sua abordagem hermenêutica, a saber a dialética da questão e da resposta:

[A definição de Gadamer] segundo a qual “o que é clássico não necessita primeiramente da superação da distância histórica, pois, em mediação constante, realiza por si só essa superação" capa à relação de pergunta e resposta constitutiva de toda tradição histórica. (...) Mesmo ante a obra clássica a consciência que opera com base na história do efeito não se encontra desobrigada da tarefa de identificar “a relação de tensão entre texto e presente”. O conceito (...) de clássico que interpreta a si mesmo só pode conduzir à inversão da relação histórica de pergunta e resposta e contradizer o princípio da história do efeito segundo o qual o entendimento "não é um processo apenas reprodutivo, mas produtivo também"

Segundo Jauss, a ênfase gadameriana na dimensão ontológica da compreensão

of the horizon, but not the temporal priority, of the first reading; this horizon of aesthetic understanding may also be gained only in the course of rereading or with the help of historicist understanding. Aesthetic perception is no universal code with timeless validity, but rather like aesthetic experience - is intertwined with historical experience. (...) Literary interpretation must compensate with the three achievements of the hermeneutic process for the fact that aesthetic perception itself is subject to historical exchange. It thereby gains the opportunity of broadening historicist knowledge through aesthetic understanding, and perhaps of constituting, through its unconstrained kind of application, a corrective to other applications that are subject to situational pressures and the compulsions of decision-making”. Id., p. I48.

53 A esse respeito, ver: Wagner, Irmgard. "Hans Robert Jauss and classicity". In: Comparative Literature, v. 99, n. 5 (dez., 1984), pp. II73-II84.

${ }^{54}$ Jauss, $A$ história da literatura como provocação à teoria literária. Op. cit., p. 38. 
produz uma visão excessivamente passiva do processo de mediação temporal:55 um desvio que seria corrigido pela auto-compreensão metodológica da compreensão como tarefa que requer a mediação entre horizontes temporais distintos, enfatizando o caráter ativo da interpretação: deve-se preservar o conceito de horizonte e a dinâmica da história dos efeitos tal como Gadamer os formulou. 56 mas deslocar o peso do pertencimento à tradição para o esforço de mediação - esforço esse metodicamente informado: ${ }^{57}$ Haveria, para Jauss, uma contradição entre as dimensóes ontológica e epistemológica da compreensão, a ser resolvida por meio de um reequilíbrio de forças via reabilitação de procedimentos metodológi-

ss "Mesmo o efeito das grandes obras literárias do passado não é um acontecer que se mediava a si próprio, nem pode ser comparado a uma emanação: também a tradição da arte pressupóe uma relação dialógica do presente com o passado, relação esta em decorrência da qual a obra do passado somente nos pode responder e 'dizer alguma coisa' se aquele que hoje a contempla houver colocado a pergunta que a traz de volta de seu isolamento. Onde, em Wabrbeit und Methode, a compreensão (...) é entendida como 'penetração num acontecer da tradição no qual passado e presente mediavam-se continuadamente', aí tem de padecer o 'momento produtivo que a compreensão encerra'.” Id., p. 40.

56 “(...) the insight that a 'positive and productive possibility of understanding' lies in temporal distance itself. Distance in time is to be put to use and not - as historicism would have it - overcome, that is, abolished through a one-sided transplanting of the self into the spirit of the past. The horizons of the past and the present must necessarily be contrasted before they are fused if the text in its otherness is to serve as a means of appraising the interpreter's prejudice and, finally, of allowing the interpretation to become an experience that changes the person experiencing it". Jauss, Hans Robert. Question and Answer: Forms of dialogic understanding. Minneapolis: University of Minnesota Press, 1989, p. 205.

57 “( $(. .$.$) the self-understanding proposed in Gadamer's hermeneutics, oriented as it is toward$ a history of being, and insofar as it would trace all undestanding back to 'entering into the process of transmitting the tradition', would negate the basic thrust of his theory of the historical and dialogic nature of understanding (...). The contradiction between contrasting horizons and fusing them, between an active and a passive definition of understanding in Truth and method, seems, therefore, to be obvious. To resolve it would entail opting either for a hermeneutics that mediates the tradition, and that attempts to retrospectively demonstrate the validity of the truth claim made by that which has been handed down, or for a hermeneutics of historicity that would take on the task of producing a dialogic exchange of understanding in the fullest sense - a dialogue between the text and the interpreter, between the tradition and the present, that is open to the future". Id., p. 205. 
cos de interpretação ${ }^{88}$ Como resultado, a concepção gadameriana de tradição como síntese passiva oriunda da fusão de horizontes seria abandonada em prol de uma análise da produtividade da mediação de horizontes na recepção pelos leitores, uma recepção, como vimos, que pode - e deve - ser metodicamente fundamentada $\$ 9$

Vejamos suscintamente como Gadamer responde ao desafio de Jauss.

\section{A circularidade da compreensão e o caráter incontornável da ontologia}

Refletindo sobre Verdade e método vinte e cinco anos após sua publicação, Gadamer retorna à questão da obra de arte como desafio ao modelo dialógico da compreensão:

O que ocorre (...) com a obra de arte e especialmente com a obra de arte no âmbito da linguagem? Será possível falar ali de uma estrutura de diálogo da compreensão e do entendimento? Pois não há autor que possa fazer as vezes de um interlocutor que responde, e não há nenhuma coisa em discussão, que seja deste ou daquele modo. A obra textual sustenta-se por si mesma. Aqui, a dialética da pergunta e resposta, se é que ela ocorre, parece dar-se numa única direção, isto é, a partir daquele que procura compreender a obra de arte, que a interroga, se questiona e procura escutar a resposta da obra. Sendo

58 “(...) a need for a hermeneutics of dialogicity, (...) a hermeneutics that would place responsive self-understanding enabled by the other on an equal footing with shared understanding enabled by an object as a matter of epistemological interest.” Id., p. 214.

59 "(...) the task of distinguishing between the two sides in the text-reader relationship, that is, between the effect, which is conditioned by the text, and the reception, the concretization of meaning, which is dependent on the reader, was left to the literary-historiographic process itself. Contrary to appearances, the formation of a tradition does not come about so to speak of its own accord as a passive synthesis, a 'fusion of horizons'. The 'event' produced by the literary work turned out to be a moment in the process of mediation between two horizons, between the horizon of experience evoked, confirmed, or surpassed by the work, and the horizon of experience that accompanies the receiver - an active synthesis involving understanding and then understanding differently”. Id., p. 225. 
um, esse sujeito poderá, como ser pensante, exercer ao mesmo tempo o papel de quem pergunta e de quem responde, como acontece no diálogo real entre duas pessoas. Esse diálogo consigo mesmo do leitor que busca compreender não parece contudo um diálogo com o texto, que é fixo e, como tal, acabado. Ou não? Existirá, na verdade, um texto acabado e pronto: ${ }^{60}$

Para Gadamer, importa acima de tudo sublinhar o caráter inesgotável da compreensão de uma obra de arte: como não há propriamente uma "resposta" vinda dela, não se pode jamais dar a compreensão como encerrada, mas apenas apreendê-la na forma de interpretaçóes ocasionais que compóem esse processo infinito G $^{-1}$ circularidade da compreensão aponta igualmente para a indissociabilidade da experiência estética e da ancoragem existencial; em outras palavras, não se pode, segundo Gadamer, distinguir radicalmente entre a experiência da arte e demais experiências, pois toda e qualquer experiência de sentido possui os mesmos traços fundamentais e engendra os mesmos meta-processos de compreensão. Operar arbitrariamente essa cisão é o que permitiria a Jauss pretender dominar epistemologicamente a experiência estética e deflacionar - ainda que parcialmente - seu caráter propriamente ontológico, face ao qual nossos esforços são sempre limitados ${ }^{62}$

${ }^{60}$ VM II, p. I3-I4 [7].

6I "A obra de arte caracteriza-se sobretudo pelo fato de jamais podermos compreendê-la completamente. Isso quer dizer que se nos aproximarmos dela e a interrogarmos jamais receberemos uma resposta definitiva a partir da qual possamos afirmar 'agora eu sei'. Dela não se extrai nenhuma informação precisa - e pronto! Não se podem haurir de uma obra de arte as informações que ela esconde em si, de modo a esvaziá-la como ocorre com comunicados que recebemos. A recepção de uma obra poética (...) apresenta-se como um movimento circular, no qual as respostas repercutem em novas perguntas e provocam novas respostas. (...) Uma obra de arte jamais se esgota. Ela nunca está vazia. (...) Nenhuma obra de arte nos fala sempre do mesmo modo. E a consequência é que nós também precisamos responder cada vez de modo diferente. Diferentes sensibilidades, diferentes percepçôes, diferentes aberturas fazem com que a configuração única, própria, una e mesma - a unidade da expressão artística - se manifeste numa multiplicidade inesgotável de respostas”. VMII, p. I4 [7].

62 “(...) não estou convencido de que a 'experiência estética', que Jauss tenta fazer valer, satisfaça à experiência da arte. Este era exatamente o ponto nuclear do meu conceito de 'indistinção 
Com efeito, Gadamer parece opor uma compreensão infinita, interminável à medida em que algo do sentido sempre escapa a nossos esforços de apreensão, e interpretaçôes finitas, das quais nos servimos empírica e pragmaticamente na concretude da experiência. Nesse sentido, o erro de Jauss seria o de tomar esta por aquela e, com isso - a partir de uma generalizaçáo indevida de um momento do compreender - pretender recolocar a ilusão de controle epistemológico no centro da compreensão.

Exemplo disso seria a própria constituição do horizonte de aparição de uma obra, o qual, para Gadamer, já pressuporia por si só a fusão de horizontes rejeitada por Jauss:

Estou longe de afirmar que o modo como uma obra de arte fala à sua época e ao seu mundo (o que H. R. Jauss chama de sua "negatividade") não ajuda a determinar seu significado, ou seja, o modo como ela nos fala. Este era realmente o núcleo da consciência da história dos efeitos, a saber, pensar a obra (Werk) e seu efeito (Wirkung) como a unidade de um sentido. O que descrevi como fusão de horizontes representa a forma como essa unidade se realiza. Esta não permite ao intérprete falar de um sentido originário de uma obra sem que na compreensão da mesma já não esteja sempre implicado o sentido próprio do intérprete. Toda vez que se pensar, por exemplo, que é possível "romper" o círculo da compreensão, através do método histórico-crítico (...), se está ignorando essa estrutura hermenêutica fundamental. (...) A elaboração do horizonte histórico de um texto já é sempre uma fusão de horizontes. O horizonte histórico não pode ser erigido primeiramente por si ${ }^{63}$

estética', segundo a qual a experiência estética não pode ser isolada, de tal forma que a arte se torne um mero objeto de fruição. O mesmo ocorre (...) com a 'recusa' de Jauss da fusão de horizontes. (...) a distinção do horizonte representa um momento integral no processo de investigação hermenêutica. A reflexão hermenêutica ensina, no entanto, que jamais se consegue realizar plenamente essa tarefa, por razóes essenciais, e que isto não demonstra a debilidade de nossa experiência. A investigação da recepção não pode querer liberar-se das implicações hermenêuticas, contidas em toda interpretação”. VM, p. 22-23 [14].

${ }^{63}$ VMII, p. 540-54I [475]. 
Jauss não teria se dado conta - ao menos não de maneira suficientemente satisfatória para Gadamer - do papel e da influência do horizonte presente da recepção na constituição inclusive do horizonte passado de emergência de uma obra. É dizer, a maneira como determinamos quais questóes uma obra colocou à sua época é indissociável do nosso olhar presente para essa obra e essa época. Segundo Gadamer, seria impossível separar - quer seja fenomenologicamente quer seja metodicamente - os horizontes: a fusão está pressuposta na pré-compreeensão. ${ }_{4}^{64}$

Portanto, quando Jauss pretende reequilibrar a consciência da dimensão ontológico-existencial da compreensão com as promessas epistemológicas da fundamentação metódica, o que ele faz não é senão suspender arbitrária e ilusoriamente a primeira para poder - ou crer poder - estabelecer de maneira científica a segunda. Para Gadamer, Jauss cairia nos mesmos problemas do historicismo estético, como exposto na primeira parte de Verdade e método - e na primeira seção deste artigo. A contradição apontada por Jauss entre uma compreensão passiva e uma compreensão ativa - esta última negligenciada por Gadamer - não se sustenta, dado que pressupóe a possibilidade de pensar a compreensão de si do intérprete face à obra do pertencimento a seu próprio horizonte como condição dessa mesma compreensão - por mais crítica e transformadora que ela venha a ser.

Em suma, a despeito da crítica feita por Jauss ao historicismo, Gadamer procura mostrar como a estética da recepção recai ela mesma nos mesmos problemas. O modelo hermenêutico da compreensão, que se firma na consciência das condiçôes existenciais de possibilidade - o enraizamento temporal, a "linguisticalidade” da compreensão, etc. - da compreensão, reabilita o caráter cognitivo da experiência da obra de arte neste que parece ser o único lugar que lhe cabe: não

${ }^{64}$ Numa dimensão mais elementar, a própria constituição de um “eu” e um “tu” na estrutura dialógica já pressupõe essa fusão: "Dizemos, por exemplo: a compreensão e o mal-entendido se dão entre um eu e um tu. Mas já a simples formulação 'um eu e um tu' testemunha uma alienação impressionante. Isso simplesmente não existe. Não existe nem 'o' eu nem 'o' tu. Existe apenas um eu que diz 'tu' e que diz 'eu' frente a um tu. Mas essas são situações já sempre precedidas pelo entendimento. (...) poder chamar o outro de 'tu' pressupõe sempre um profundo consenso. Já existe ali um suporte permanente. Mesmo onde tentamos entender-nos a respeito de questóes que dividem nossas opinióes, sempre está em jogo esse suporte, mesmo que raramente o saibamos”. VMII, p. 259 [223]. 
como o que se esforça a todo custo para satisfazer os requisitos de fundamentação próprios às ciências, mas como saber prático, consciente de sua vinculação ontológica a partir da qual formulações metodológicas preservam sua valência, agora desprovidas da ilusão totalitária que as caracterizara.

\section{Conclusão}

Neste artigo, buscou-se examinar a relação entre verdade e método na filosofia hermenêutica, a partir da experiência da obra de arte. O que estava em jogo era, de um lado, se ainda se pode fazer valer pretensóes de verdade quando se trata de compreender um fenômeno artístico e, de outro lado, qual papel - se algum procedimentos metódicos ocupariam na busca pela verdade nessa dimensão da experiência.

Partindo da crítica de Gadamer à consciência estética, voltada tanto contra seu esvaziamento de valor cognitivo quanto contra uma tentativa de atrelar a verdade artística a uma abstração conceitual, retomou-se o caráter eminentemente prático - no sentido aristotélico - do saber que se pode ter sobre a arte. A reconstrução esboçada aqui teve como ponto de chegada o reconhecimento do caráter ontológico da experiência estética e, nesse sentido, da incapacidade de distingui-la radicalmente da experiência em geral.

Ao opor à filosofia hermenêutica gadameriana a estética da recepção de Jauss, a questão foi recolocada no sentido de retomar sobre outras bases a tentativa de fundamentação epistemológica da experiência estética. Com efeito, tratou-se de questionar a pertinência da solução ontológica de Gadamer no tocante à história dos efeitos e à fusão de horizontes, indagando em que medida uma descrição fenomenológica da experiência da recepção artística articulada em torno das operações de compreender, interpretar e aplicar não forneceria uma resposta satisfatória aos anseios de se formular um método para lidar com fenômenos artísticos de maneira a preservar os ganhos da filologia crítica e escapar aos perigos do historicismo ingênuo. Com Jauss, lidamos com a objeção segundo a qual Gadamer teria se enredado numa concepção demasiado passiva da compreensão, a qual deveria ser contrabalanceada pela atividade crítica da recepção, cujos procedimentos preservariam caráter cognoscitivo. 
Finalmente, de modo breve, a defesa gadameriana aparece como lembrete e advertência à estética da recepção: esta, no afã de preservar algum sentido de cientificidade, acaba por descrever arbitrária e artificialmente a experiência estética, incorrendo na mesma parcialidade da qual buscava escapar. Ao fim e ao cabo, não é possível a nós, seres temporalmente situados, escapar desse enraizamento existencial e pretender dominar e esgotar - ainda que provisoriamente - o sentido de um fenômeno artístico qualquer.

Não se pretendeu, aqui, esgotar a questão - afinal, isso implicaria uma contradição performativa com a perspectiva hermenêutica da qual se partiu. O privilégio conferido a uma análise mais detalhada de uma pequena parte da magnum opus de Gadamer, bem como daquilo que na obra de Jauss the diz diretamente respeito, em detrimento de um tratamento sistemático tanto da natureza da experiência estética na obra de ambos teve como objetivo apenas levantar o problema e enfatizar a tensão entre ontologia e epistemologia que atravessa a filosofia hermenêutica ao menos desde Heidegger. O saldo da discussão parece apontar tanto para a necessidade de reabilitação do valor cognitivo da experiência estética quanto para o caráter inescapável do enraizamento ontológico dessa experiência.

\section{Referências}

COBIÁN, Mario Ramírez. "O legado estético de Gadamer”. In: Princípios, v. I9, n. 3I (2OI2), pp. 53-64.

FIGURELLI, Roberto. "Hans Robert Jauss e a estética da recepção". In: Letras, V. 37 (1988), pp. 265-285.

GADAMER, Hans-Georg. Verdade e método. 32 edição. Petrópolis: Vozes, 1999. . Verdade e método II. Petrópolis: Vozes, 2002.

GUTIÉRRES-POZO, Antonio. "El arte como realidad trasformada en su verdad.

La rehabilitación hermenéutica de la estética en Hans-Georg Gadamer”. In: Kriterion, n. 139 (abr. 2018), pp. 35-54.

HAIDU, Peter. "The semiotics of alterity: A comparison with hermeneutics". In: New Literary History, v. 2I, n. 3 primavera, 1990, pp. 67I-691.

JAUSS, Hans Robert. A história da literatura como provocação à teoria literária. São Paulo: Ática, 1994. 
- Question and answer: Forms of dialogic understanding. Minneapolis: University of Minnesota Press, 1989. . Toward an aesthetic of reception. Minneapolis: University of Minnesota Press, 1982.

WAGNER, Irmgard. "Hans Robert Jauss and classicity”. In: Comparative Literature, v. 99, n. 5 (dez., 1984), pp. II73-II84.

Resumo: A relação entre verdade e método, central na filosofia hermenêutica de Hans-Georg Gadamer, tem na consciência estética seu lugar privilegiado de emergência. Sua análise do caráter ontológico da obra de arte pretende reabilitar o conteúdo cognitivo da experiência artística sobre outras bases que a do método científico, paradigma da epistemologia moderna. Hans Robert Jauss se colocou em debate com Gadamer, apresentando sua estética da recepção como formulação alternativa de fundamentação propriamente epistemológica da experiência estética. Neste artigo, trata-se de contrapor os dois autores para, a partir deles, pensar a relação entre verdade, ontologia e epistemologia no âmbito da arte.

Palavras-chave: Hermenêutica; Estética; Hans-Georg Gadamer; Hans Robert Jauss.
Aвstract: The relation between truth and method, key to Hans-Georg Gadamer's hermeneutic philosophy, has in aesthetic experience its privileged ground. Hs analysis of the ontological aspect of the artwork intends to rehabilitate the cognitive content of artistic experience on new bases, other than the scientific method paradigmatic to modern epistemology. Hans Robert Jauss has placed himself in debate with Gadamer, setting forth his aesthetics of reception as an alternative path towards proper epistemological grounding of aesthetic experience. In this paper, both authors will be put against one another in order to, taking up from them, conceive the relationship between truth, ontology, and epistemology in the realm of art.

KeYwords: Hermeneutics; Aesthetics; Hans-Georg Gadamer; Hans Robert Jauss. 